\title{
How Tanzanian Nurse-Midwives and Obstetricians Develop Postpartum Relationships With Women
}

\author{
Columba Mbekenga, Megan Aston, Danielle Macdonald, Keisha Jefferies, \\ Sheri Price, Lilian T. Mselle, Gail Tomblin Murphy, Thecla W. Kohi, \\ Shawna O'Hearn, and Maureen White
}

\begin{abstract}
Nurse-midwives and obstetricians are the primary postpartum health-care providers for mothers and babies in Tanzania. It is imperative that mothers and babies receive adequate information and support in order to save lives. Feminist poststructuralism and discourse analysis were used to conduct and analyze 13 semi-structured interviews from nurse-midwives and obstetricians at three clinics in Dar es Salaam, Tanzania. Establishing friendly supportive relationships enabled nurse-midwives and obstetricians to work effectively with mothers postpartum. Participants explained the importance of including family members in postpartum care and about the strategies they used in a clinic environment that was not always supportive of including family. Effective relational maternity care focused on families during the postpartum period can facilitate the delivery of information and save lives.
\end{abstract}

KEYWORDS: postpartum; Tanzania; poststructuralism; discourse analysis; feminism; qualitative; nurse-midwife; obstetrican

In Tanzania, maternal and newborn health is a national priority. In particular, it is important for mothers and newborns to receive appropriate health care and support during the postpartum period, which is defined by the World Health Organization (WHO) as immediately after birth and up to 6 weeks. It is a critical time for women, as approximately $50 \%$ of maternal and neonatal deaths occur within the first 24 hours, and $75 \%$ within 7 days (National Bureau of Statistics and ICF Macro, 2011). It is of great concern that only $34 \%$ of mothers come for a health-care visit within 48 hours after delivery (National Bureau of Statistics, 2016), even though this practice is encouraged by health-care practitioners. In Tanzania, nurse-midwives and obstetricians are the primary care providers during the postpartum period and provide thorough assessments, education, and support to mothers and families at hospital clinics. Many challenges for attending postpartum care services have been identified, such as lack of transportation, inadequate financial resources, and attitudes of health-care workers. Therefore, it is imperative that nurse-midwives and obstetricians establish trusting relationships with mothers while they are still in the hospital and before they return home so that they can impart important information in an effective manner and encourage them to return to the hospital clinic for follow-up about any concerns. In this article, we discuss the importance of creating supportive relationships, one of the major themes from our qualitative exploratory study that examined postpartum care encounters between nurse-midwives, obstetricians, and mothers in three health facilities located in Dar es Salaam, Tanzania.

\section{LITERATURE REVIEW}

Maternal and infant mortality and morbidity rates continue to be of great concern to health-care professionals, 
the government, and the people of Tanzania, with the maternal mortality ratio at 556 per 100,000 and the infant mortality rate at 43 per 1,000 live births (MoHCDGEC, $\mathrm{MoH}$, NBS, OCGS, \& ICF, 2016). Safety during birth is a high priority; however, the postpartum period is also recognized as an important time to monitor mothers and infants for danger signs, with the intent of preventing death. The postpartum period includes 6 weeks following the birth of the baby/babies and placenta (World Health Organization, 2013). During the postpartum period, it is important to monitor infant nutrition including breastfeeding and other feeding methods, infant care, infant immunizations, HIV testing and/or treatment of mothers, and management of other complications that may arise, including postpartum depression, infections, and obstetric fistulae. For example, the leaking of urine and feces due to obstetric fistulae can have negative impacts on social, cultural, and physical health (Hilton, 2003; Mselle, Moland, Evjen-Olsen, Mvungi, \& Kohi, 2011).

The alarming statistics demonstrate the need to continue to search for ways to reduce mortality rates and improve quality of life. This includes a comprehensive understanding of how multiple issues affect mothers and infants during the postpartum period. Accessibility to adequate postpartum services and information is crucial to improve the mortality and morbidity rates in Tanzania. This includes hospitals, clinics, and healthcare professionals, as well as effectively sharing knowledge with mothers and their families.

The Ministry of Health and Social Welfare (MOHSW) conducted a community assessment in 2009 and found that many Tanzanian women, their partners, and community leaders understood the importance of appropriate antenatal care (ANC) and HIV screening during pregnancy; however, their knowledge was lacking regarding postpartum care and only included an awareness of immunization and child growth-monitoring cards. Community members cited lack of available transportation, costs associated with delivery in a facility, and the attitude of health providers as barriers to a positive and accessible health-care system. Another concern is the lack of involvement of husbands. In Lugina's and Sommerfeld's (Lugina \& Sommerfeld, 1994) groundbreaking qualitative research, they found that the involvement of men was lacking due to reinforced cultural notions of gender roles. This lack of involvement created a deficiency of knowledge about the importance of prenatal and postpartum care and information for both the men as well as women, and thus many women did not attend antenatal clinics.
They also found there was minimal use of postpartum services immediately before discharge and for the first follow-up visit at the clinic. Inclusion of men during prenatal and postpartum clinic visits continues to be low and this is a concern that health-care professionals are attempting to address (Mbekenga, Pembe, Christensson, Darj, \& Olsson, 2011; Mbekenga, Pembe, Darj, Christensson, \& Olsson, 2013). Adequate breastfeeding education and "father-supported breastfeeding" have been specifically identified as important factors to reduce mortality rates through exclusive breastfeeding, which enhances immunity to illnesses (Mbekenga, Lugina, Christensson, \& Olsson, 2011b; Mlay, Keddy, \& Stern, 2004). Findings from a systematic review show that male involvement is associated with reduced postpartum depression and improved utilization of maternal services including postnatal care (Yargawa, LeonardiBee, \& , 2016), thereby indicating the need to involve fathers in postpartum care.

It is also important to understand how mothers are supported by other informal caregivers in the community, including family, community members, neighbors, and traditional birth attendants (Mbekenga, Pembe, Christensson, Darj, \& Olsson, 2011; Mbekenga, Christensson, Lugina, \& Olsson, 2011a). While the intentions were good, many new parents stated they received contradictory health information that caused confusion as they had to decide whether to follow the advice from health-care professionals or informal caregivers (Lugina, Christensson, Massawe, Nystrom, \& Lindmark, 2001).

The complexity of issues and concern for the safety of mothers and newborns, and the belief that women should birth in hospitals, not at home, positions nurse-midwives and obstetricians as experts whereby they are responsible for delivering effective support, information, and education to women and families. We were interested in examining how this happened in Tanzania. The White Ribbon Alliance is an international organization and has an office located in Tanzania. This organization advocates for respectful maternity care, which requires health-care professionals to build positive relationships with women during their maternity care. Respectful maternity care was initially endorsed by the WHO to address the maltreatment of women during childbirth in low- and middle-income countries, but has since expanded to include all countries. Most of the literature about respectful maternity care focuses on the prenatal and birthing periods, with fewer articles focusing on the postpartum period. There is also an extensive body of literature focusing on relationships between midwives and women; yet most of the research has 
focused on midwifery practice in developed countries and it includes relationships that develop over months before and after birth. Tanzania is different because continuity of care, that is, the same health-care provider providing perinatal care to the same woman for each encounter she has with the health-care system, is generally absent, or it occurs by chance. Nurse-midwives in Tanzania are not able to spend a lot of time with women in the prenatal or postpartum clinics. Therefore, we wanted to understand what their unique experiences were, knowing they were probably working within conditions that were underresourced in terms of time and space. It is crucial that accurate and consistent postpartum information and support be imparted to mothers, babies, and their families in a manner that is accessible, acceptable, meaningful, and useful to mothers. We wondered how and if this was being done.

Although we recognized the Tanzanian context was unique and different from developed countries, we still looked to the relational midwifery and nursing literature. For example, Hunter (2006) interviewed 19 midwives in the United Kingdom to examine the relationships between midwives and mothers and concluded that reciprocity and emotional investment were important to providing effective care. Reed, Rowe, and Barnes (2016) conducted a qualitative study in Australia and conceptualized the relationship between midwives and mothers to be "ritual companionship." Both authors recommended that supportive relational practices should be included between midwives and women; however, further studies are needed to understand the nuances of different contexts. In Norway, researchers conducted a qualitative study about women's experiences of midwifery care during postpartum home visits (Dahlberg, Haugan, \& Aune, 2016). In this study, Dahlberg et al. (2016) concluded that "relational continuity" between midwives and new mothers was important in order for the emotional aspects of the birth and postpartum period to be attended to. Relational continuity was described by Dahlberg et al. (2016) as an ongoing relationship developed over time between an expecting/new mother and a midwife/health-care provider.

In the United Kingdom, Boyle, Thomas, and Brooks (2016) conducted interviews with 16 women to understand whether the U.K. agenda of partnership with women and supporting choice in midwifery care is wanted by women or it has been realized. Boyle et al. (2016) identified the role and importance of relationships between women and midwives as one of the key themes of the study. Women articulated their desire for continuity of care, that is, care provided by the same midwife or group of midwives, and the need for ample time to develop a relationship with the midwife or midwives who provided care to them.

In New Zealand, Noseworthy, Phibbs, and Benn (2013) conducted a qualitative study that explored the current issues involved in decision-making in midwifery care. Noseworthy et al. (2013) interviewed eight midwife-woman pairs and concluded with a proposal that a relational decision making model in midwifery care could account for the intersections and complexities of multiple contextual factors that inform how decisions are made by and between women and midwives. Key to the integration of relational decision making in midwifery care is the element of what Noseworthy et al. (2013) describe as "relational trust," where trust is developed between the woman and midwife through the development of their relationship.

Given that previous research highlights the importance of relationships between women and midwives in countries located in the global North, we were interested to see how this aspect of midwifery care was realized in Tanzania, a country in the global South. Although the contexts may vary between countries in the global North and countries in the global South, it was important to explore how relational maternity care is being provided in the postpartum period in Tanzania. We were also interested to see how relational maternity care may be informing the goal of respectful maternity care as established by the White Ribbon Alliance and supported by the WHO.

\section{STATEMENT OF THE PROBLEM}

A key component in reducing maternal mortality and morbidity, for the improvement of maternal health, is to foster caring and therapeutic relationships between nurse-midwives, obstetricians, and mothers during the postpartum period so that information and support can be provided. Therefore, it is essential to understand how and if nurse-midwives and obstetricians form and nurture these caring relationships with postpartum mothers. Understanding these socially and institutionally constructed processes and the experiences of everyday practices will enable policy makers, researchers, educators, and health-care professionals to develop and provide effective care strategies to postpartum women that may include resources to facilitate supportive relationships. We decided to begin our exploration by interviewing nurse-midwives and obstetricians. A follow-up study was then conducted to examine the experiences of postpartum women. 


\section{RESEARCH PURPOSE AND QUESTIONS}

The purpose of this qualitative investigation was to explore the experiences of nurse-midwives and obstetricians during their provision of postpartum care to mothers at three clinics in Dar es Salaam, Tanzania, with the intent of discovering what the most important issues were for the participants. Our research questions were as follows: (a) What are the experiences of nursemidwives and obstetricians at the hospitals/clinics during the postpartum period? (b) How do personal, social, and institutional discourses affect postpartum care? (c) How do relationships affect postpartum care?

\section{METHODOLOGY}

We used feminist poststructuralism (FPS) to guide this qualitative investigation (Butler, 1992; Cheek, 2000; Foucault, 1983; Scott, 1992; Weedon, 1987), which included a Foucauldian understanding of the relations of power. FPS requires an analysis of any and all socially constructed positions that arise when interviewing participants, such as gender, race, ethnicity, culture, and abilities. We also used discourse analysis to deconstruct and understand participants' beliefs, values, and practices within social and institutional discourses (Aston, 2016). Personal stories and experiences provided evidence to understand how nurse-midwives and obstetricians negotiated relations of power with new mothers and within the health-care system. We trusted that the personal stories and perspectives of participants were authentic in terms of their lived experience and personal meaning. We had no reason to doubt their experiences and found there were more similarities among them than differences. They did speak about families having different perspectives from themselves, which alerted us to the importance of understanding that there are multiple experiences and interpretations of the same situation. Therefore, conducting further studies with mothers was recommended.

Foucault challenges us to think differently about power. Rather than thinking of power as a dominant force that acts upon people, Foucault believed that all people had power and used it in relational encounters to position themselves and work through both empowering and oppressive situations. Subjectivity and agency were also important concepts used to collect and analyze the data. Subjectivity focuses on the personal location of participants in relation to social and institutional discourses. For example, being a nurse-midwife has certain meanings and practices attached to the position. The same person can also have other subject positions such as woman, daughter, and artist that are apparent when one is positioned in particular ways in relation to others. The concept of agency allows for an analysis of how someone negotiates power, depending on the subject position. In this research, we examined how nursemidwives and obstetricians worked within social and health-care systems that influenced how they supported and offered information to mothers at the hospital clinics. These decisions entailed choosing, negotiating, and challenging certain discourses and practices. In other words, participants used their agency through different relations of power.

\section{Participant Recruitment}

Letters of invitation were sent to regional medical officers (RMOs) requesting permission to recruit participants from regional hospitals and their affiliated health centers in selected regions of Dar es Salaam. Once permission was granted from the RMO, the regional hospitals and health centers were contacted directly by members of the research team. Unit managers were asked to identify and recommend nurse-midwives and obstetricians at each health facility and to provide the contact information of potential participants. Each nurse-midwife and obstetrician was privately contacted and offered the opportunity to learn more about the study. To be considered eligible to participate in this study, the participants had to be nurse-midwives or obstetricians providing postpartum care to women in Dar es Salaam, employed in one of the three regional hospitals or affiliated health centers of interest for a minimum of 1 year, and able to read, speak, and understand Kiswahili. Eligible participants were given the opportunity to ask questions and learn more about the study. Participants were also informed of the possibility that their manager or other staff members could become aware of their participation in the study, resulting in the inability to ensure anonymity. Despite this, measures were taken to protect the identity and confidentiality of participants and their information. Study participants were recruited from three regional hospitals and their affiliated health centers using purposeful sampling. Ten nurse-midwives and three obstetricians were recruited from the Temeke, Mwananyamala, and Amana hospitals in the Temeke, Kinondoni, and Ilala Districts. 


\section{Data Collection and Ethics}

Ethical approval for this study was obtained from Dalhousie University, Muhimbili University of Health and Allied Sciences, Commission for Science and Technology, and the National Institute of Medical Research before recruitment and data collection began. Each of the study participants provided written and verbal informed consent prior to the interviews. The study participants were informed of their right to end the interview at any point, to refuse to answer any question, or to withdraw from the study as late as 1 month following the interview. Each of the face-to-face interviews lasted 60-90 minutes and followed a semi-structured interview guide. Interviews were audio recorded and conducted in a private location convenient for each participant. The interviews were conducted in Kiswahili by research team members who were native Kiswahili speakers. Audiotapes were transcribed verbatim and then translated into English for analysis.

\section{Data Analysis}

We used feminist poststructuralist discourse analysis (Aston, 2016) to understand the beliefs, values, and practices of nurse-midwives and obstetricians in the context of their relationships with mothers. All members of the research team were taught how to use feminist poststructuralist discourse analysis. Although FPS encourages an open interpretive analysis using specific concepts, we also followed guiding steps as documented by Aston (2016). These relate to (a) identifying important issues, (b) applying beliefs, values, and practices in the transcripts, (c) including social and institutional discourses, (d) understanding how participants respond to relations of power, and (e) including subjectivity and agency. Emerging themes were discussed as a team after each team member independently analyzed a minimum of two interviews. Any discrepancy or disagreement about the analysis or emerging themes was discussed and a consensus was reached. The trustworthiness of the study was attended to through the use of methods such as triangulation of findings among team members, keeping an audit trail, and using verbatim quotations (Lincoln \& Guba, 1985).

\section{FINDINGS}

Nurse-midwives and obstetricians spoke about the importance of creating supportive relationships with mothers and family members during the short time they had with them in the postpartum clinics. Participants believed that connecting with mothers and establishing a trusting relationship was needed before they could effectively support and share information with them. Quickly building trust was necessary in order to enable mothers to share information about themselves with the nurse-midwife or obstetrician. In particular, there were three main themes focusing on the importance of relationships: (a) building friendly and family-focused relationships with mothers, (b) developing relationships with family members in the care of mothers, and (c) nurse-midwives and obstetricians sensitively addressing difficult health topics.

\section{Building Friendly and Family-Focused Relationships With Mothers}

In order to provide effective postpartum care to mothers, all of the participants spoke about the importance of building trusting relationships. To attain this, they described how they would treat mothers such as a family member or a friend. This was a purposeful way to think about and relate to mothers as they believed it would help them develop safe, comfortable, and trusting relationships that would facilitate open dialogue. For example, one nurse-midwife shared the following, in the context of HIV testing:

If she received education in this room, I became her friend. She might say she was afraid to test, so I would counsel her to come with her husband. Later on I would counsel him so they would not lose their kids. (NM1)

This nurse-midwife believed that it was important to quickly establish a friendly relationship with mothers for a few reasons. For example, if the mother was afraid, being friendly would help the counseling process and create a connection that could also extend to family members. She also alluded to the belief that having HIV was a sensitive and potentially socially difficult situation that had to be addressed in a sensitive and kind manner, which required the support of the family. In her position as an expert nurse-midwife, she believed that the way she offered knowledge and care was just as important as what she was offering. She knew that practicing in a friendly manner would be the most effective way to care for the mother and her husband. Using concepts from FPS, we can see how she shifted her subject position as 
an expert health-care professional, who might be perceived as someone having more power, to a "friendlier" position such as a family member, who might make the mother feel less nervous, afraid, or intimidated. She was able to shift her position of power through the way she interacted with mothers and family members. This could be interpreted as moving between an institutional health-care discourse and a social family discourse that has different beliefs about relationships.

The same nurse-midwife provided another example of how she explored another mother's home situation by first becoming her "friend" so she could then ask sensitive questions through gentle probing. Her comments are similar to those of other participants, as the majority said they needed to explore a mother's family situation and incorporate family assessments as often as possible. For example, nurse-midwives and obstetricians would ask about economic circumstances so that they could offer appropriate suggestions about how to be safe and healthy at home.

First you must ask the mother, "What is your income at home?" You need to consider that although you can give health education to the mother, that mother might not be able to afford those things. So you must first build a friendship with the mother, then you can probe the mother. When you become friends she will tell you, "I am keeping chickens, I cultivate, I don't have another source of income." So you understand her needs, and that is how you will find a way to give advice to the woman. (NM1) this as an important practice that helps them with their work tells us that we need to pay attention.

Similar to other nurse-midwives and obstetricians in the study, this nurse-midwife valued relationships with the mothers and families in her care. She recognized how a friendly relationship with women allowed her to uncover further personal information that then enhanced her ability to provide appropriate health information and care. For this nurse-midwife, the ability to build relationships or, as she stated, "building a friendship" was powerful. It was a way of negotiating and shifting power relations. She had expertise and power in terms of her knowledge of health information and health care; yet, she also recognized that women had expertise and power in terms of how they made decisions about their own lifestyle and health. Paying attention to details and feelings helped the nurse-midwives and obstetricians connect with and support mothers and families.

All participants spoke about how the high ratio of mothers to nurse-midwives and obstetricians affected the care they provided to mothers. This created heavy workloads and short periods of time that they could spend with mothers. Although the participants shared how busy they were at work, they also spoke about their passion for and commitment to caring for mothers and babies to keep them safe. This is often what kept them going and able to provide care. For example, one nurse-midwife said:
To understand the meaning of "friend" within the Tanzanian hospital setting, we needed to pay attention to the context. This nurse-midwife recognized that she needed to be sensitive to the mothers' circumstances so that she could both understand and make appropriate suggestions for care. It was more than simply providing information, it was how she connected with and provided information to the mothers. She had to provide information that made sense to their lifestyle. Some might say that being kind, nice, or friendly is a normal everyday practice that should simply and naturally occur. However, using FPS requires us to constantly question everyday practices to understand the meaning and relations of power that exist and impact care. The fact that all participants raised
And they really challenge us. Some days you do not want to teach the mothers, or check mothers. For example you left home tired, but you find as the time goes, you find it uncomfortable and start assessing them. You think what if it was you or your relatives what you would have done? (NM3)

Her words indicate that she holds compassion and commitment for mothers, babies, and families. She described herself as hardworking and an expert who can effectively assess mothers and babies. She told us that she pushed herself even though she was tired in order to provide good care to mothers. Although she was tired and experienced a conflict between fatigue and compassion, she chose to follow her compassion, as described by her comparison of others to herself and her own family, and pushed herself to work hard. She appeared to feel an ethical dilemma between meeting her own physical needs and the needs of others and it was a real struggle to provide care at times. She subjectively positioned herself as a 
nurse-midwife who must carry out her duties at the clinic. She also subjectively positioned herself as a human being who may feel tired and want to slow down and rest.

\section{Developing Relationships With Family Members in the Care of Mothers}

Many participants spoke about the importance of including family members in the care of mothers. While it was not usually feasible to invite family members in with the mothers, the majority of nurse-midwives and obstetricians tried to include family when possible. The following two quotations are from nurse-midwives describing the importance of family.

While an assessment is completed and relatives are provided instructions for the woman who does not understand, we utilize relatives and we even instruct mothers to come with a relative to the clinic after seven days. We have seen the advantage of using relatives and when they arrive to us, we ask her "Who accompanies you to the clinic?" She will say, "I have come with a relative," so we normally involve relatives. (NM3)

Another nurse-midwife gave the example of including and educating fathers:

When we talk about danger signs for the mother and for the child when the father is here, he could know these signs and could know what to do; maybe to come early to the hospital, and this sign I should go to the main hospital and know in advance what to prepare and who should be left at home. (NM8)

All participants valued time spent with mothers and families, since this would enable them to better support mothers; however, lack of space also limited the ability of nurse-midwives and obstetricians to spend time with mothers and families. If family members could not be invited in, then they would stress the importance of including family in their care when they returned home.
So we ask her who will be close with you and we provide health education on how to do self-care, we tell her that nowadays we don't use hot water because it can later lead to anaemia. We counsel those who have delivered for the first time because when they go home and tell their relative not to use hot water they might not understand her, but for those who have delivered multiple times, they are easily understood by relatives. (NM7)

Unfortunately, when nurse-midwives and obstetricians were unable to include family members, it put them in a difficult situation as they told us that some mothers believed the health-care professionals were "not considering them." The institutional shortage of health-care professionals created difficult situations whereby mothers might not trust them if they felt they were not being adequately cared for.

Some participants spoke about mothers who came to the hospital by themselves. This was concerning for both nurse-midwives and obstetricians and created ethical dilemmas for some. Confidentiality was also of utmost importance as described by one obstetrician.

The patient has her own right if she wants her husband to know her problem... If she wants her problem to be known by her mother or father, she is also allowed to do this. She might use nurses or doctors to give information to those whom she wants to know, otherwise the patient is protected by her rights. We as health care professionals, are not allowed to breach confidential information of the patient unless granted permission by the patient herself. But in terms of advice for example, someone who has come to the hospital and has no food, there must be a small discussion to deliberately seek her relatives such as her husband. Or if it is the girl who lives with parents, we have to see her parents. A person needs to get medicine and needs to eat. Now if someone will stay here without eating anything we have to search for relatives. A client may be prescribed a medication and supposed to buy and take it. A day or so may pass without taking that medicine and in that case we need to communicate with her relatives. (OB6) 
We can see how this obstetrician believed in the importance of respecting mothers' confidentiality and that it was an important part of building trusting relationships and supporting mothers. The obstetrician also spoke about how permission must be obtained from the mother first; however, if the mother was in a difficult situation where she had no food or medicine, the obstetrician said they would push harder to see if they could encourage the mother to reconnect with family. One nurse-midwife described how she and others valued family support and therefore would work hard to try and reunite disadvantaged mothers with their families. This was difficult because while they did not want to breach confidentiality, they also wanted mothers to have family support.

What we can do is to trace their history. You may find the woman is not staying in town and had an unintended pregnancy or maybe she was a prostitute. She might need more counseling because she can neglect or abandon the child due to an inability to support that child. So we talk with them and arrange for them to be taken back to their home. We send her to her parents where she can receive enough care, the hospital support and bus fare. They are transported to their home but we do not have the time and space to talk with the individual's family. (NM8)

All nurse-midwives and obstetricians believed that family should be included in a mother's health care and participate in postpartum education at hospital clinics. Unfortunately, there was most often not enough time and space to include family members. Including the family is an important issue especially in light of the research literature cited earlier that has shown that the involvement of fathers can help improve health outcomes for mothers and newborns.

\section{Nurse-Midwives and Obstetricians Sensitively Addressing Difficult Health Topics}

Although the nurse-midwives and obstetricians believed in developing positive relationships with mothers and their families and worked hard to attain this type of relationship with mothers, this work also involved positioning themselves at times between the mothers and their extended family if family members had different beliefs about postpartum care. For example, one nursemidwife stated:

You might find if the mother had pregnancy induced hypertension, you would tell her "I have discharged you because your pressure has improved. You should continue to take these medications and you need to have a notebook for recording your blood pressure." You find other mothers do not go, but some do go. We tell them after seven days to come back to the hospital. Those who come, we see them again instead of going to other Reproductive and Child Health $(\mathrm{RCH})$ clinics because we instruct them to come to our RCH clinic. Those who disappear, when they come they are really sick, you find they have high pressure and are having seizures. And those with anemia, most of them they have received hot water massage; we normally instruct them not to use hot water. When they go home, they go see a grandmother who is old, she would burn them with hot water massage, you may find that they are brought to us with $\mathrm{Hb}$ of 8 when they come back, you find their anemia is very serious... . Now what I think, first they don't take medicine which they have been given and second the uterus is not healed so if it is burnt with hot water from the place where placenta was attached it starts to bleed. (NM3)

Many of the nurse-midwives and obstetricians told us that grandmothers and older women in the community continued to promote the practice of hot water massage into the abdomen among postpartum women for cleansing purposes. Nurse-midwives and doctors tried to educate mothers not to do this as it was a dangerous practice where the heat would cause excessive bleeding and anemia.

Another nurse-midwife also believed that all mothers needed as much information as possible and that it needed to be delivered in a nonthreatening way because of the stigma associated with hospital clinics; in particular, clinics that were associated with HIV. She spoke about how she assured mothers that HIV was a routine test for all mothers so as not to stigmatize or deter mothers from being tested and encouraged them to come back to the clinic at the required times. 
Those are the ones who came to us, because those who are discharged from the postnatal ward, we normally tell them they have to come to the clinic after seven days regardless of their condition, whether they are sick or well. When you tell them to go to the clinic they think about testing for HIV so we normally tell them that their progress has to be assessed after delivery. (NM3)

Nurse-midwives had to work sensitively with mothers and their families and respect confidentiality in a variety of ways. For example, writing an HIV status on a woman's health record could be devastating and therefore some women chose to change their status from positive to negative on the "card." They would then verbally disclose to the nurse-midwife that their status was positive.

So we know them. A woman coughs but you find the card is all plain. We normally tell them that we have this routine here you cannot go out, and it is the policy of the nation, every mother must be tested for HIV. So there are those who fudged the card, and she looks for you before you start calling. She tells you that, "I had to change my status on the card because you know at home..." And if you test her again you find it is true. So we are using these procedures to check the card. (NM3)

This nurse-midwife recognized that some mothers needed to hide their HIV status and therefore did not always rely on the information on the cards. The stigma of HIV affected the care provided by this nurse-midwife. She was aware of the stigma and attempted to open the dialogue with each mother. As a nurse-midwife, she was in a position of power and knew that she could influence a mother's health not only with health information regarding herself and her baby, but she could also address the social stigmatization of HIV testing by trying to normalize it through regular institutional scheduled visits. Social and institutional beliefs and values about HIV/AIDS conflicted and therefore needed to be addressed by the nurse-midwives and obstetricians in a way that was supportive of mothers.
Compassion and commitment was evident in the way participants spoke about supporting and building relationships with mothers and their families.

My opinion is entirely in the nursing profession. People need to change their attitude. They have to like their job, to work hard with heart. Those who do well, we try our best to improve more but if they change their attitude everything will be good. So those who do not work with one heart they have to do that. (NM8)

Sensitivity and compassion were clearly important elements when caring for mothers. In particular, connections with family were very important and informed the way nurse-midwives and obstetricians handled sensitive situations. There appeared to be a strong social and cultural discourse about the importance of family that ultimately directed the care given by nurse-midwives and obstetricians.

\section{DISCUSSION}

Therapeutic relationships have been documented extensively as an essential aspect of health care globally and have been shown to improve health outcomes and result in positive health-care experiences (Wright \& Leahey, 2013; Belcher \& Jones, 2009). Similar to our findings in Tanzania, Aston et al. (2015) also found that public health nurses and mothers in Nova Scotia, Canada, believed supportive relationships were an essential part of caring for mothers and families during the postpartum period. More specifically, Aston et al. (2015) focused on the importance of how public health nurses needed to be friendly, approachable, polite, calm, and welcoming for an effective relationship to develop between the mothers and the nurses. Although we are comparing two different cultures and the contexts are different, it is important to note the similarities. The public health nurses in Canada and nurse-midwives and obstetricians in Tanzania all used the words "friend," "friendly," and "family" when describing their relationships with the mothers for whom they cared. Nurse-midwives and obstetricians believed they needed to develop supportive relationships that began with a personal connection. In their own words they described this connection as treating women like family and friends. It is important 
to note the way in which they described their interactions and relationships. Being "friendly" was purposeful and it was more than just being nice. Treating others as you would your own family members speaks to a cultural discourse about family in Tanzania. From the perspective of the participants in our study, relationships with and ways of relating to friends and family not only guided personal interactions, but they also guided professional practice. This social discourse informed the way nurse-midwives and obstetricians negotiated relations of power with mothers. They chose to begin their meetings with mothers in a nonhierarchical and nonthreatening way because they believed they should develop a particular type of relationship, even if they only had a very short amount of time.

Being friendly positioned nurse-midwives and obstetricians as caring and trustworthy and enabled them to engage more easily with mothers. Participants all described how mothers would then be more forthcoming with personal and sensitive information such as their economic situations. Understanding personal and sensitive aspects of the mothers' lives enhanced their ability to assess and provide appropriate health information. The nurse-midwives and obstetricians described being sensitive to each individual mother's circumstance and ensured that they provided information and recommendations that would make sense for the mother's daily lifestyle. The ability of nursemidwives and obstetricians to interact with mothers in a friendly manner and to provide friendly supportive care was also found in a study by Rosen et al. (2015) who observed that respectful maternity care that was friendly was implemented during the first stage of labor in $86 \%$ of cases in Tanzania, Kenya, Rwanda, and Madagascar. Although they did not examine the postpartum period, this study highlighted the importance of being friendly and respectful during perinatal care.

The findings of our study are significant because they demonstrate how nurse-midwives and obstetricians in Tanzania integrate and experience respectful maternity care and why they think it is so important. The importance of providing respectful care to women during perinatal care has been highlighted by the White Ribbon Alliance (2011) as a women's human rights issue. According to the White Ribbon Alliance (2011), the relationships that mothers develop with their maternity care providers are essential for ensuring healthy outcomes, and they can help to empower women as they begin or continue their motherhood journey. Nurse-midwives and obstetricians in our study valued the development of relationships with the mothers they provided care to and believed that it was necessary to develop this type of relationship in order to ensure that they could provide life-saving support and information to mothers and their families. They used their skills and expertise to provide respectful care despite the challenges they faced regarding staff shortages and inconsistent access to resources.

The implications of staff shortages and the dangers of compromising physical and emotional safety are evident in other studies that examined the provision of maternity care. For example, in a study by Mselle, Moland, Mvungi, Evjen-Olsen, and Kohi (2013), nursemidwives in Tanzania reported how frequent staff shortages impacted their ability to care for women during labor and delivery. The nurse-midwives often prioritized high-risk women because of their acute medical needs, which meant that other women were left alone (Mselle et al., 2013). During staff shortages, the nurse-midwives did not have time to meet the physical needs of all the birthing women in their care, and the nurse-midwives certainly did not have time to develop therapeutic relationships with them. Although the study by Mselle et al. (2013) was about labor and delivery, and not the postpartum period, it is important to note the serious problems that arise with staff shortages.

Similarly, in Canada, Segaric \& Hall, 2015) found that if nurses are short-staffed, they are less likely to pursue personal connections with patients and family members, but would focus on tasks or just doing the job. Not surprisingly, Segaric and Hall (2015) also found that patients and families were more likely to comply or cooperate with nursing care when nurses showed interest in learning more about patients and family members. In the same study, Segaric and Hall (2015) found that positive interpersonal dynamics among nurses, patients, and their families motivated participants to pursue personal connections by sharing details about their lives. Positive interpersonal relationships between nurses and patients/families are likely to create a sense of trust among care providers and clients, hence resulting in increased quality of care. In all of these examples, the relationships that health-care providers develop with the individuals and families in their care are integral to an overall positive experience with the health-care system and positive health-care outcomes.

In our study, nurse-midwives and obstetricians valued mothers as agents in their own care, recognizing their individual power and therefore did not treat them as passive recipients of care, but as experts on their own health. Similarly, a study that explored how public health nurses (PHNs) support mothers and families 
during postpartum home visits in Nova Scotia, Canada, found that PHNs treated the mothers as experts and ensured that the visits were client led; hence, power dynamics was shifted from nurses to mothers (Aston et al., 2015). According to the findings from the study by Aston et al. (2015), mothers were/are empowered to take control and make decisions about their own health, a desired aspect for strengthening maternal and child health.

By examining the experiences of nurse-midwives and obstetricians who care for mothers during the postpartum period, it became evident that they valued establishing supportive, trusting relationships with mothers and with families. They were also highly committed and passionate about their work. However, this was often difficult to achieve in a resource-restricted environment. All participants spoke about the importance of developing relationships quickly and sensitively in order to gain trust and impart life-saving information. Similar to studies cited earlier, the participants in our study emphasized the importance of family involvement in the care of the mothers during the postpartum period. However, there were barriers to engaging families, including limited space, limited time to talk to mothers due to workload, and high nurse-patient ratio. It was difficult for participants to challenge and negotiate the relations of power that restricted their practice and ultimately went against their moral beliefs and values.

Participants described providing extra care for disadvantaged mothers or handling ethical dilemmas when their beliefs about family support did not align with the practices of mothers who were on their own. Sensitivity and careful attempts to reconnect mothers with their families was a common theme that emerged from this study. However, the social and cultural discourse of the importance of families also conflicted with the practices of health-care professionals at times, who had to abide by confidentiality for the mothers. Some participants spoke about the importance of protecting mothers from family who may not know about their HIV status. This entailed careful assessments and understandings of what mothers wanted and honoring their choices.

The nurse-midwives and obstetricians in our study did note that mothers and their families at times held negative views of health-care providers because they could not always fulfill their promises. As we have demonstrated, the institutional support was not supportive of their practices. Other researchers have documented that the public holds negative views of nurse-midwives in Tanzania and other low- and middle-income countries (Mselle et al., 2013; Mannava,
Durrant, Fisher, Chersich, \& Lüchters, 2015). However, our research challenges these views. Overall, the nursemidwives and obstetricians in our study spoke about how compassion and commitment in supporting and building relationships with mothers and their families was integral to their practice.

\section{CONCLUSION}

The nurse-midwives and obstetricians in our study clearly gave examples of how they personally "negotiated" power with mothers in a supportive and empowering way with the intent of supporting the health and safety of mothers, babies, and their families. However, the institutional discourses that created barriers of time, space, and increased workload conflicted with the values and beliefs of nurse-midwives and obstetricians who wanted to provide more relational and holistic care to mothers.

\section{Strengths and Limitations}

The descriptive narratives provided by nurse-midwives and obstetricians provide compelling evidence regarding the importance of establishing trusting relationships with mothers and their families. Although our research was specific to one area in Tanzania, the in-depth analysis of experiences could be transferable, as practitioners can decide if findings from our study are relevant to their practice in other low- and middle-income countries and apply if appropriate in their hospital context. Although transferability of findings is a strength, we also need to remind the reader that our findings are not generalizable due to the specific context and small number of participants.

\section{Recommendations}

1. It is important to develop trusting, "friendly" professional relationships with mothers in order to support healthy and safe outcomes.

2. Family-centred care is an important part of supporting mothers postpartum. When possible, include family members.

3. Nurse-midwives and obstetricians are trained and able to conduct sensitive and thorough assessments. Ensure institutional support is available to health- 
care professionals to implement thorough and sensitive assessments.

What does this article contribute to the wider global clinical community?

1. Developing trusting, "friendly" professional relationships with mothers is a global health issue that supports mothers and families during the postpartum period.

2. Family-centred care is an important global health issue that needs to be part of supporting mothers postpartum.

3. The training of nurse-midwives and obstetricians is a global health issue that requires academic and clinical institutional support.

\section{REFERENCES}

Aston, M. (2016). Teaching feminist poststructuralism: Founding scholars still relevant today. Creative Education, 07(15), 2251-2267. http://dx.doi.org/10.4236/ce. 2016.715220

Aston, M., Price, S., Etowa, J., Vukic, A., Young, L., Hart, C., . . . Randel, P. (2015). The power of relationships. Journal of Family Nursing, 21(1), 11-34. http://dx.doi.org/10.1177/ 1074840714561524

Belcher, M., \& Jones, L. K. (2009). Graduate nurses experiences of developing trust in the nurse-patient relationship. Contemporary Nurse, 31(2), 142-152. http://dx.doi.org/ 10.5172/conu.673.31.2.142

Boyle, S., Thomas, H., \& Brooks, F. (2016). Women's views on partnership working with midwives during pregnancy and childbirth. Midwifery, 32, 3221-3229. http://dx. doi.org/10.1016/j.midw.2015.09.001

Butler, J. (1992). Contingent Foundations: Feminism and the Question of "Postmodernism". In J. Butler \& J. Scott (Eds.), Feminists theorize the political (pp. 3-21). New York and London: Routledge, Chapman and Hall, Inc.

Cheek, J. (2000). Postmodern and poststructural approaches to nursing research. Thousand Oaks. CA: Sage.

Dahlberg, U., Haugan, G., \& Aune, I. (2016). Women's experiences of home visits by midwives in the early postnatal period. Midwifery, 39, 3957-3962. http://dx.doi.org/10. 1016/j.midw.2016.05.003

Foucault, M. (1983). The subject and power. In H. L. Dreyfus \& P. Rainbow (Eds.), In Michel Foucault, beyond structuralism and hermeneutics (2nd edpp. 208-226). Chicago: University of Chicago Press.
Hilton, P. (2003). Vesico-vaginal fistulas in developing countries. International Journal of Gynecology \& Obstetrics, 82(3), 285-295. http://dx.doi.org/10.1016/S00207292(03)00222-4

Hunter, B. (2006). The importance of reciprocity in relationships between community-based midwives and mothers. Midwifery, 22(4), 308-322. http://dx.doi.org/10. 1016/j.midw.2005.11.002

Lincoln, Y. S., \& Guba, E. G. (1985). Naturalistic inquiry. Beverly Hills, CA: Sage Publications.

Lugina, H., Christensson, K., Massawe, S., Nystrom, L., \& Lindmark, G. (2001). Change in maternal concerns during the 6 weeks postpartum period: A study of primiparous mothers in Dar Es Salaam, Tanzania. Journal of Midwifery \& Women's Health, 46(4), 248-257. http:// dx.doi.org/10.1016/S1526-9523(01)00133-7

Lugina, H. I., \& Sommerfeld, D. M. (1994). Postpartum concerns: A study of Tanzanian mothers. Health Care for Women International, 15(3), 225-233. http://dx.doi. org/10.1080/07399339409516114

Mannava, P., Durrant, K., Fisher, J., Chersich, M., \& Lüchters, S. (2015). Attitudes and behaviours of maternal health care providers in interactions with clients: A systematic review. Globalization and Health, 11, 36. http://dx.doi. org/10.1186/s12992-015-0117-9

Mbekenga, C. K., Christensson, K., Lugina, H. I., \& Olsson, P. (2011a). Joy, struggle and support: Postpartum experiences of first-time mothers in a Tanzanian suburb. Women and Birth, 24(1), 24-31. http://dx.doi.org/10.1016/ j.wombi.2010.06.004

Mbekenga, C. K., Lugina, H. I., Christensson, K., \& Olsson, P. (2011b). Postpartum experiences of first-time fathers in a Tanzanian suburb: A qualitative interview study. Midwifery, 27(2), 174-180. http://dx.doi.org/10.1016/j. midw.2009.03.002

Mbekenga, C. K., Pembe, A. B., Christensson, K., Darj, E., \& Olsson, P. (2011). Informal support to first-parents after childbirth: A qualitative study in low-income suburbs of Dar es Salaam, Tanzania. BMC Pregnancy and Childbirth, 11(1), 98. http://dx.doi.org/10.1186/ 1471-2393-11-98

Mbekenga, C. K., Pembe, A. B., Darj, E., Christensson, K., \& Olsson, P. (2013). Prolonged sexual abstinence after childbirth: Gendered norms and perceived family health risks. Focus group discussions in a Tanzanian suburb. BMC International Health and Human Rights, 13(1), 4. http://dx.doi.org/10.1186/1472-698X-13-4

Ministry of Health, Community Development, Gender, Elderly and Children [Tanzania Mainland], Ministry of Health $(\mathrm{MoH})$ [Zanzibar], National Bureau of Statistics, Office of the Chief Government Statistician, and ICF. (2016). Tanzania Demographic and Health Survey and MalariaIndicator 
Survey (TDHS-MIS) 2015-16. Dar es Salaam, Tanzania, and Rockville, Maryland, USA: MoHCDGEC, MoH, NBS, OCGS, and ICF.

Mlay, R. S., Keddy, B., \& Stern, P. N. (2004). Demands out of context: Tanzanian women combining exclusive breastfeeding with employment. Health Care for Women International, 25(3), 242-254. http://dx.doi.org/10. 1080/07399330490272741

Mselle, L. T., Moland, K. M., Evjen-Olsen, B., Mvungi, A., \& Kohi, T. W. (2011). "I am nothing": Experiences of loss among women suffering from severe birth injuries in Tanzania. BMC Women's Health, 11(1), 49. http://dx. doi.org/10.1186/1472-6874-11-49

Mselle, L. T., Moland, K. M., Mvungi, A., Evjen-Olsen, B., \& Kohi, T. W. (2013). Why give birth in health facility? Users' and providers' accounts of poor quality of birth care in Tanzania. BMC Health Services Research, 13(1), 174. http://dx.doi.org/10.1186/1472-6963-13-174

National Bureau of Statistics. (2016). Tanzania Demographic Health Survey - Malaria Indicator Survey [TDHS-MIS]. (2016). Tanzania.

National Bureau of Statistics and ICF Macro. (2011). Tanzania Demographic and Health Survey.

Noseworthy, D. A., Phibbs, S. R., \& Benn, C. A. (2013). Towards a relational model of decision-making in midwifery care. Midwifery, 29(7), e42-e48. http://dx. doi.org/10.1016/j.midw.2012.06.022

Perry, E. P., Hockenberry, M. J., Lowdermilk, D. L., Wilson, D., Keenan-Lindsay, L., \& Sams, C. (2013). Maternal child nursing in Canada. New York, NY: Elsevier-Mosby.

Reed, R., Rowe, J., \& Barnes, M. (2016). Midwifery practice during birth: Ritual companionship. Women and Birth, 29(3), 269-278. http://dx.doi.org/10.1016/j.wombi.2015.12.003

Rosen, H. E., Lynam, P. F., Carr, C., Reis, V., Ricca, J., Bazant, E. S., Bartlett, L. A., \& Quality of Maternal and Newborn Care Study Group of the Maternal and Child Health Integrated Program. (2015). Direct observation of respectful maternity care in five countries: a cross-sectional study of health facilities in East and Southern Africa. BMC Pregnancy and Childbirth, 15(1), 306. http://dx.doi.org/10.1186/s12884015-0728-4

Scott, J. W. (1992). Experience. In J. Butler \& J. W. Scott (Eds.), Feminists theorize the political (pp. 22-40). New York, NY: Routledge, Chapman and Hall, Inc.

Segaric, C. A., \& Hall, W. A. (2015). Progressively engaging: Constructing nurse, patient, and family relationships in acute care settings. Journal of Family Nursing, 21(1), 35-56. http://dx.doi.org/10.1177/1074840714564787

Waldenström, U., Brown, S., McLachlan, H., Forster, D., \& Brennecke, S. (2000). Does team midwife care increase satisfaction with antenatal, intrapartum, and postpartum care? A randomized controlled trial. Birth, 27(3), 156-167. http:// dx.doi.org/10.1046/j.1523-536x.2000.00156.x

Weedon, C. (1987). Feminist practice and poststructuralist theory. New York, NY: Basil Blackwell Ltd.

White Ribbon Alliance. (2011). Respectful maternity care: The universal rights of childbearing women. Washington, DC: The White Ribbon Alliance for Safe Motherhood.

World Health Organization. (2013). WHO recommendations on postnatal care of the mother and newborn. Retrieved from http://apps.who.int/iris/bitstream/handle/ 10665/97603/9789241506649_eng.pdf?sequence $=1$

Wright, L., \& Leahey, M. (2013). Nurses and families: guide to family assessment and intervention. Philadelphia, PA: FA Davis.

Yargawa, J., \& Leonardi-Bee, J. (2016). Male involvement and maternal health outcomes: Systemic review and meta analysis. Journal of Epidemiology and Community Health, 1-9.

Correspondence regarding this article should be directed to Megan Aston, PhD, MEd, BScN, RN, School of Nursing, Dalhousie University 5869 University Ave, Halifax, Nova Scotia, Canada B3H 4R2. E-mail: megan.aston@dal.ca

Columba Mbekenga, PhD, MSc.PH, BScN, School of Nursing and Midwifery, Aga Khan University, Dar es Salaam, Tanzania, East Africa.

Megan Aston, PhD, MEd, BScN, RN, School of Nursing, Dalhousie University, Halifax, Nova Scotia, Canada.

Danielle Macdonald, MSN, BSC, School of Nursing, Dalhousie University, Halifax, Nova Scotia, Canada.

Keisha Jefferies, BScN, RN, School of Nursing, Dalhousie University, Halifax, Nova Scotia, Canada.

Sheri Price, PhD, MSN, RN, School of Nursing, Dalhousie University, Halifax, Nova Scotia, Canada.

Lilian T. Mselle, PhD, MSc, BScN, School of Nursing, Muhimbili University of Health and Allied Sciences, Dar es Salaam, Tanzania, East Africa.

Gail Tomblin Murphy, PhD, MSN, RN, School of Nursing, Dalhousie University, Halifax, Nova Scotia, Canada.

Thecla W. Kohi, PhD, MSN, BScN, RNM, School of Nursing, Muhimbili University of Health and Allied Sciences, Dar es Salaam, Tanzania, East Africa.

Shawna O'Hearn, MA, MSc (OT), Global Health Office Dalhousie University, Halifax, Nova Scotia, Canada.

Maureen White, MSN, RN, School of Nursing, Dalhousie University, Halifax, Nova Scotia, Canada. 